\title{
Removal of lead from water using biochars prepared from hydrothermal liquefaction of biomass
}

\author{
Zhengang Liu, Fu-Shen Zhang* \\ Research Center for Eco-Environmental Sciences, Chinese Academy of Sciences, 18 Shuangqing Road, Beijing 100085, PR China
}

\section{A R T I C L E I N F O}

\section{Article history:}

Received 22 July 2008

Received in revised form

26 November 2008

Accepted 21 January 2009

Available online 30 January 2009

\section{Keywords:}

Biomass

Heavy metal

Adsorption isotherm

Adsorption kinetic

\begin{abstract}
A B S T R A C T
Hydrothermal conversion of biomass into biofuel could produce a special type of biochar as byproduct. This biochar is quite different from biochar derived from high temperature pyrolysis. In the present study, two biochars, prepared from hydrothermal liquefaction of pinewood (P300) and rice husk (R300), were characterized and investigated for lead removal from aqueous solution. The results indicated that the biochars contained a large amount of oxygen-containing groups on the surface, which were quite effective for lead removal with capacities of 4.25 and $2.40 \mathrm{mg} / \mathrm{g}$ for P300 and R300, respectively. The adsorption equilibrium was achieved around $5 \mathrm{~h}$. Higher temperature favored the removal capacity implying that the adsorption was an endothermic process. The adsorption data at optimum solution $\mathrm{pH} 5$ could be well described by Langmuir model and the adsorption process was well fitted by pseudo-second-order model. Moreover, it was found that the adsorption was mainly controlled by film diffusion. Thermodynamics analysis suggested that lead adsorption onto the biochars was physical endothermic process.
\end{abstract}

(C) 2009 Elsevier B.V. All rights reserved.

\section{Introduction}

The removal of heavy metals from contaminated water has become a major research topic due to the toxicological problems caused by the toxic metals to the environment and to human health in recent years. Among the various methods, adsorption has been proven to be an efficient technology while its large-scale application is limited by the high cost of the adsorbent. Under this situation, some raw industrial and agricultural byproduct (RIAB) and RIABbased carbonaceous materials as low cost adsorbents have been tested to evaluate their efficiency in the removal of heavy metals $[1,2]$. For example, peat has been proven to be an excellent adsorbent for metal ions removal from wastewater, especially at the low ion concentration [3]. The ability of poplar sawdust to bind heavy metal ions was investigated and the result showed that the metal ions were selectively adsorbed on the sawdust [4]. Coconut shell has high affinity for metal ions due to the presence of functional groups such as carboxylic, lactone and phenolic hydroxylic groups [5]. However, RIAB has many disadvantages, and one of which is the leaching of organic pollutants, which may cause further pollution $[6,7]$. This problem could be simply avoided by carbonization of the raw materials. Recently birch wood was successfully converted to carbonaceous material and the product showed high mercury removal efficiency from aqueous solution [8]. Activated carbons,

\footnotetext{
* Corresponding author. Tel.: +8610 62849515; fax: +86 1062849515 .

E-mail address: fszhang@rcees.ac.cn (F.-S. Zhang).
}

prepared from rice husk and sugarcane bagasse, had good adsorption capacities with respect to arsenic, humic acid and phenol [9]. The promising results were obtained when carbonaceous material prepared from coconut shell was utilized as adsorbent for wastewater treatment [10].

Currently, hydrothermal conversion is a promising biomass-tooil approach. This process produces biochar as one of the major products and with increasing importance of bio-oil large amounts of biochar will be available in the near future [11-15]. In the field of biomass hydrothermal conversion, most attention has been focused on the liquid product (bio-oil), but the biochar, which is also an attractive byproduct, has received less attention. Thus far, there is no other valuable utilization method available for this carbonaceous residue except direct combustion for heat production.

The objective of this study was to investigate the feasibility of biochars, resulted from pinewood and rice husk hydrothermal conversion processes, as adsorbents for lead removal from aqueous solution. The ultimate goal was to find a value-added utilization approach for these byproducts.

\section{Materials and methods}

\subsection{Biochars preparation}

The biochars used in this study were obtained from a typical hydrothermal treatment process [11,12]. Briefly, $5 \mathrm{~g}$ biomass (pinewood or rice husk) was loaded with $30 \mathrm{ml}$ de-ionized water into a $100-\mathrm{ml}$ autoclave and nitrogen gas was used to purge the air 
outside the reactor. The reactor was hold at $573 \mathrm{~K}$ for $20 \mathrm{~min}$ then cooled to room temperature. The solid products were extracted by acetone to produce bio-oil and the biochars were recovered as solid residues (designated as P300 and R300 for pinewood and rice husk residues, respectively). The two biochars were then washed several times using de-ionized water. Thereafter, the biochars were dried in an oven at $378 \mathrm{~K}$ for $24 \mathrm{~h}$. The dried biochar samples were ground to less than $0.5 \mathrm{~mm}$ and kept in a desiccator for adsorption experiments.

\subsection{Chemical analysis}

Elemental analysis of the biochars was performed on a Flash EA1112 Elemental Analyzer (USA). The pH was measured using a Mettler Toledo Delta $320 \mathrm{pH}$ meter (Switzerland), and surface morphology was studied by SEM on S-3000N (Japan). Lead concentration in the filtrate was analyzed by ICP-OES (USA). Oxygen-containing functional groups were determined by Boehm titration method. Briefly, a given amount of biochar was added to the alkali solutions $\left(\mathrm{Na}_{2} \mathrm{CO}_{3}, \mathrm{NaHCO}_{3}\right.$ and $\left.\mathrm{NaOH}\right)$ and the mixture was agitated at agitating bed for $12 \mathrm{~h}$. The supernatant was then drawn and back titrated with $\mathrm{HCl}[16,17]$.

\subsection{Lead adsorption}

All chemical reagents were of analytical grade. Stock lead solution $(1000 \mathrm{mg} / \mathrm{L})$ was prepared by dissolving lead nitrate in double-distilled water. Desired solutions were prepared by dilution of the stock solution. The $\mathrm{pH}$ value was adjusted by nitric acid or sodium hydroxide. For isotherm studies, $50-\mathrm{ml}$ polythene bottle was filled with $25 \mathrm{ml}$ lead solution of different concentrations (5-40 mg/L) at different temperatures (298, 308 and $318 \mathrm{~K}$ ). The biochar was added to each bottle and agitated at $180 \mathrm{rpm}$ for $24 \mathrm{~h}$. The amount of lead removal was determined by measuring concentration difference before and after adsorption experiment.

\section{Results and discussion}

\subsection{Characterization of the biochars}

Chemical composition of P300, R300 and their parent materials are shown in Table 1 . As expected, the content of carbon in P300 and R300 were much higher and hydrogen and oxygen was much lower than their respective parent materials. The relatively higher values of $\mathrm{O} / \mathrm{C}$ and $\mathrm{H} / \mathrm{C}$ for $\mathrm{P} 300$ and R300 indicated that biomass underwent an incomplete decomposition after hydrothermal treatment. In addition, the higher content of hydrogen and oxygen for P300 implied that more activated sites available and stable carbon-oxygen complexes existed on the surface of P300 than R300 [18].

Table 1

Chemical analysis of the biochars and the parent materials.

\begin{tabular}{lcccr}
\hline Sample & Pinewood & P300 & Rice husk & R300 \\
\hline Component analysis (\%) & & & & \\
Cellulose & 37 & & 33 & \\
Hemicellulose & 38 & & 24 & \\
Lignin & 22 & 21 & \\
Moisture & 2.6 & & 4.0 & \\
Elemental analysis (\%) & & & & \\
$\mathrm{C}$ & 49.25 & 61.60 & 38.04 & 2.62 \\
$\mathrm{H}$ & 6.18 & 3.42 & 4.85 & 23.82 \\
$\mathrm{O}^{\mathrm{a}}$ & 44.27 & 34.82 & 48.46 & 0.11 \\
$\mathrm{~N}$ & 0.30 & 0.16 & 1.75 & 2.37 \\
$\mathrm{Si}$ & - & - & 6.90 & \\
\hline
\end{tabular}

${ }^{a}$ By difference-Not detected.

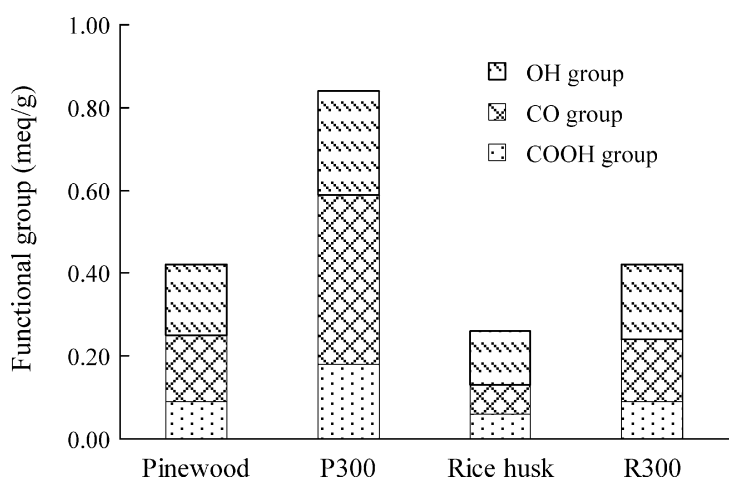

Fig. 1. Oxygen-containing functional groups in P300 and R300.

Fig. 1 shows Boehm titration results for P300 and R300. As can be seen, the content of total oxygen-containing groups increased respectively $98 \%$ and $62 \%$ for pinewood and rice husk after hydrothermal treatment. Total functional groups was $0.84 \mathrm{meq} / \mathrm{g}$ for P300 with detail content of $0.18,0.41$ and $0.25 \mathrm{meq} / \mathrm{g}$ for carboxylic, lactone and phenolic hydroxylic group, respectively. As for $\mathrm{R} 300$, total oxygen-containing functional groups was low with 0.12 , 0.12 and $0.18 \mathrm{meq} / \mathrm{g}$ for carboxylic, lactone and phenolic hydroxylic groups, respectively.

The surface property is important for biochar reactivity and the SEM images of pinewood, rice husk, P300 and R300 are shown in Fig. 2. It was noted that irregular surface of biochars with pores of different shapes and sizes was observed. Taking into account the fact that hydrolysis reaction is predominant for biomass hydrothermal treatment and the morphology change was ascribed to the hydrolysis of biomass and release of degradation products [19].

\subsection{Lead adsorption experiments}

\subsubsection{Effect of solution $p H$}

The effect of $\mathrm{pH}$ on lead adsorption was investigated in an initial $\mathrm{pH}$ range between 1.0 and 6.0 and the results are shown in Fig. 3. Generally, lead adsorption onto the biochars strongly depends on the solution $\mathrm{pH}$ and the effect on P300 is higher than R300. The removal capacity is very little at $\mathrm{pH}$ below 2.0 and increases along with the increase of $\mathrm{pH}$, reaching a plateau value at $\mathrm{pH}$ 5.0. The effect of $\mathrm{pH}$ can be explained by the surface charge of the biochars. At lower $\mathrm{pH}$, the surface functional groups (mainly oxygen-containing groups) linked to the $\mathrm{H}^{+}$, making these inaccessible for lead ions. With increasing the $\mathrm{pH}$ value, the deprotonation of functional groups provided the chance to co-ordinate with lead ions resulting in higher removal rate. While at $\mathrm{pH}$ higher than 5.0 , the decreasing trend was caused by the formation of soluble hydroxyl complexes $[20,21]$. Therefore, all the other experiments in this study were carried out at optimum initial pH 5.0 so as to achieve maximum lead removal capacity.

\subsubsection{Effect of temperature}

Adsorption studies were carried out at three temperatures 298 , 308 and $318 \mathrm{~K}$ and the results are shown in Fig. 4. The adsorption capacity increases with increasing temperature and the maximum adsorption capacities are 4.13 and $2.38 \mathrm{mg} / \mathrm{g}$ for P300 and R300 obtained at $318 \mathrm{~K}$, respectively. Higher temperature favored lead ions adsorption onto P300 and R300, suggesting that the adsorption was an endothermic process. This attributed to the sufficient energy provided by promoted temperature for lead ions to reach and adsorb onto biochar's interior structure. These results were consistent with the previous report that cation removal capacity increased with increasing temperature by seaweed in the range of 277-328 K [22]. 

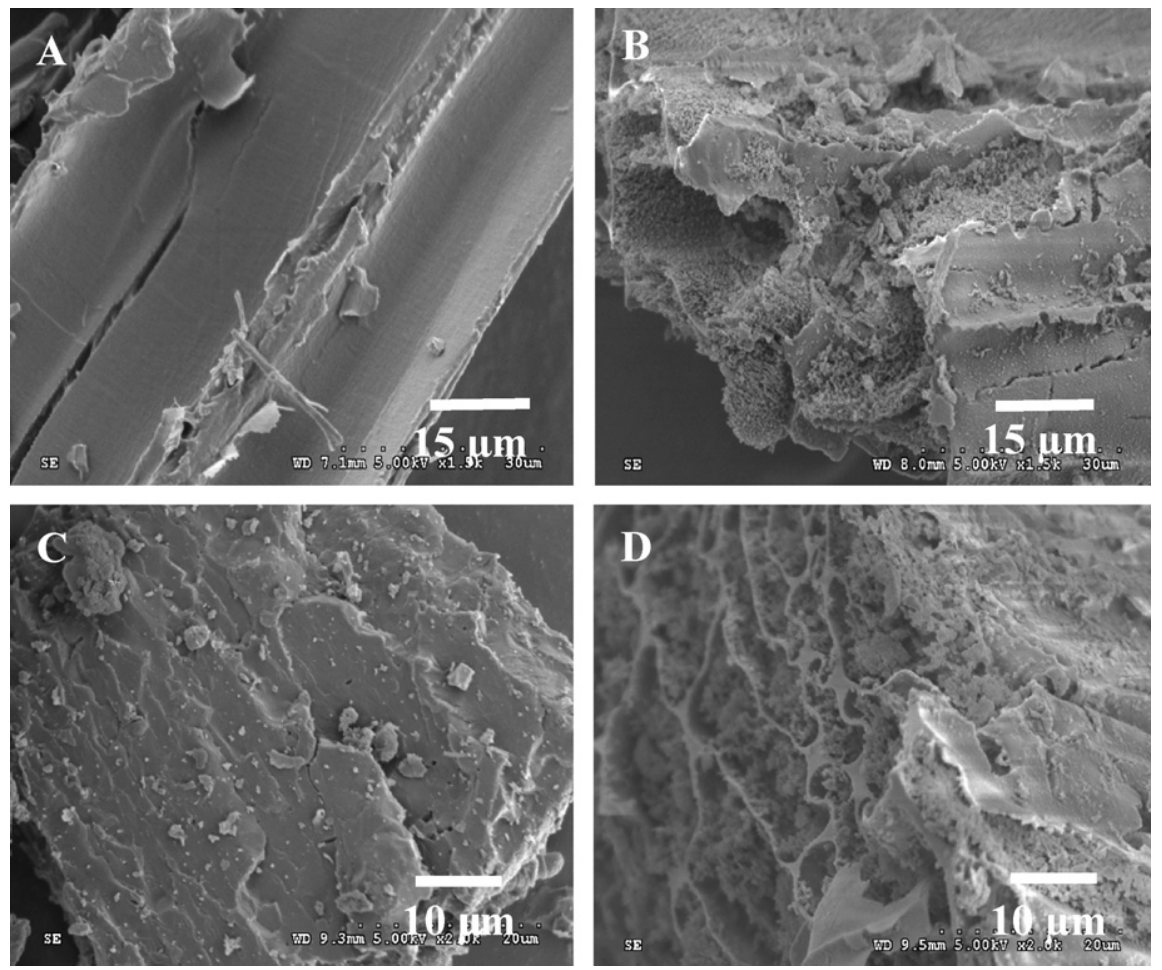

Fig. 2. SEM images of (A) raw pinewood, (C) rice husk and biochars obtained from (B) pinewood and (D) rice husk hydrothermal treatment at $573 \mathrm{~K}$.

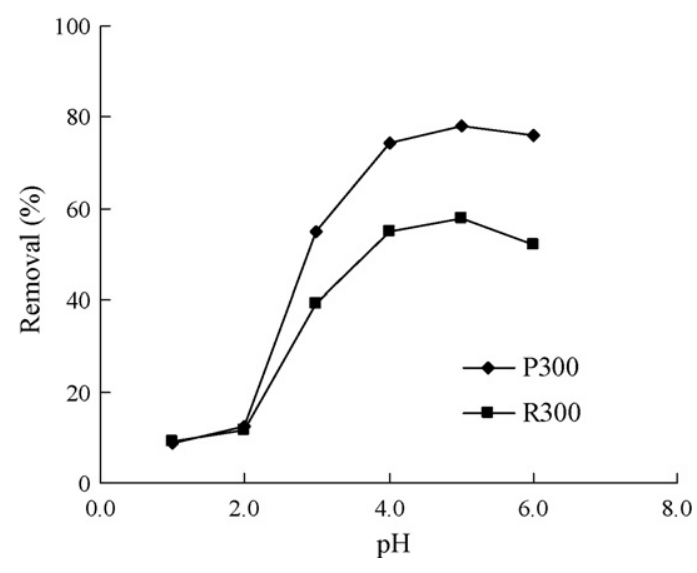

Fig. 3. Effect of initial solution $\mathrm{pH}$ on lead adsorption onto P300 and R300 (adsorbent dose $2.5 \mathrm{~g} / \mathrm{L}$; initial lead concentration $10 \mathrm{mg} / \mathrm{L}$ ).

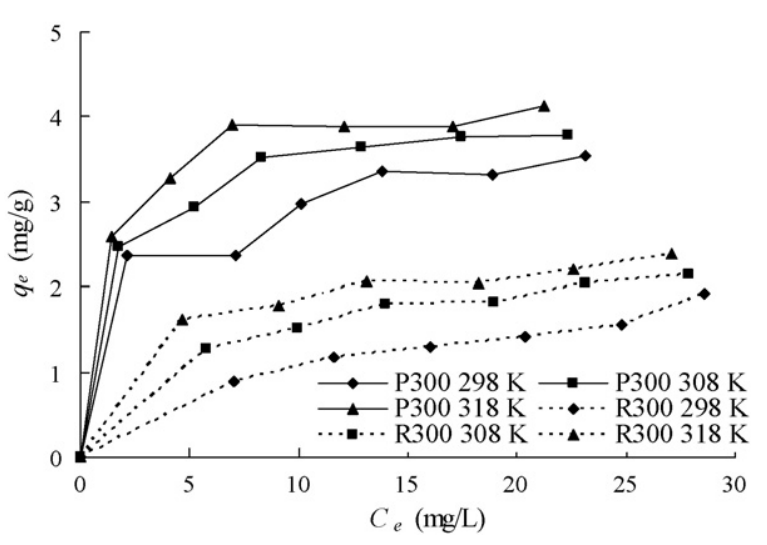

Fig. 4. Effect of temperature on lead adsorption capacity (adsorbent dose $5 \mathrm{~g} / \mathrm{L}$; initial lead concentration $5-40 \mathrm{mg} / \mathrm{L}$ ).

\subsubsection{Effects of initial concentration and contact time}

Fig. 5 presents the effect of initial concentration and contact time on lead adsorption onto P300 and R300 at $298 \mathrm{~K}$ (adsorbent dose $4 \mathrm{~g} / \mathrm{L}$ ). It indicated that the contact time for $95 \%$ removal equilibrium was less than $5 \mathrm{~h}$ in the concentration range of $10-20 \mathrm{mg} / \mathrm{L}$. For both biochars, adsorption capacity increased with the increase of solution concentration, which ascribed to a high contact probability between the biochars and lead ions. At low concentration, lead ions were located at the outer surface of the biochar independently, while with increasing the solution concentration lead ions entered into the interior structure, resulting in higher removal capacity.

\subsubsection{Adsorption isotherms}

To estimate the maximum adsorption capacity and evaluate the adsorption intensity of lead onto biochars, Langmuir and Freundlich models were used to fit the experimental data. The two models' linear forms are:

$$
\frac{C_{e}}{q_{e}}=\frac{1}{a b}+\frac{C_{e}}{b} \quad \text { (Langmuir model) }
$$

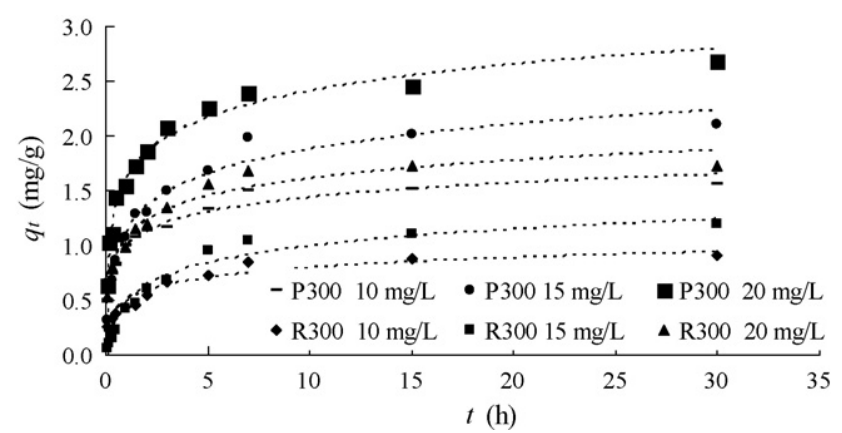

Fig. 5. Effects of initial concentration and contact time on lead removal capacity (adsorbent dose $4 \mathrm{~g} / \mathrm{L}$, temperature $298 \mathrm{~K}$ ). 
Table 2

Constants and correlation coefficients of Langmuir and Freundlich models for lead adsorption onto P300 and R300 (adsorbent dose $5 \mathrm{~g} / \mathrm{L}$ ).

\begin{tabular}{|c|c|c|c|c|c|c|c|}
\hline \multirow[t]{2}{*}{ Sample } & \multirow[t]{2}{*}{$T(\mathrm{~K})$} & \multicolumn{3}{|c|}{ Langmuir model } & \multicolumn{3}{|c|}{ Freundlich model } \\
\hline & & $a$ & $b$ & $R^{2}$ & $K_{F}$ & $n$ & $R^{2}$ \\
\hline \multirow{3}{*}{ Р300 } & 298 & 0.36 & 3.89 & 0.98 & 1.75 & 4.77 & 0.47 \\
\hline & 308 & 0.71 & 4.03 & 0.99 & 2.26 & 5.61 & 0.95 \\
\hline & 318 & 1.02 & 4.25 & 0.99 & 2.57 & 6.10 & 0.90 \\
\hline \multirow{3}{*}{ R300 } & 298 & 0.21 & 1.84 & 0.92 & 0.35 & 2.07 & 0.95 \\
\hline & 308 & 0.33 & 2.25 & 0.97 & 0.72 & 3.03 & 0.97 \\
\hline & 318 & 0.54 & 2.40 & 0.98 & 1.15 & 4.73 & 0.95 \\
\hline
\end{tabular}

$\ln q_{e}=\ln K_{F}+\frac{1}{n} \ln C_{e} \quad$ (Freundlich model)

where $C_{e}(\mathrm{mg} / \mathrm{L})$ is the equilibrium concentration in the solution, $q_{e}(\mathrm{mg} / \mathrm{g})$ the lead adsorbed at equilibrium, $b(\mathrm{mg} / \mathrm{g})$ the maximum adsorption capacity, $n$ Freundlich constant related to adsorption intensity, and $a(\mathrm{~L} / \mathrm{mg})$ and $K_{F}\left((\mathrm{mg} / \mathrm{g})(\mathrm{L} / \mathrm{mg})^{1 / n}\right)$ are the adsorption constants for Langmuir and Freundlich models, respectively.

The linearity test of two models for the adsorption of lead onto P300 and R300 at different temperatures were plotted. The experimental results are illustrated in Table 2 and Fig. 6 (298 K only). Correlation coefficients suggested that the better fitting of experimental data was Langmuir model isotherm rather than Freundlich isotherm $\left(R^{2} \geq 0.92\right.$ for Langmuir model $)$ with maximum adsorption capacity 4.25 and $2.40 \mathrm{mg} / \mathrm{g}$ for P300 and R300 at $318 \mathrm{~K}$, respectively. The parameter $a$ related to the energy of adsorption and it can be seen that P300 presented larger bond energy than R300 ( 1.02 and $0.54 \mathrm{~L} / \mathrm{mg}$ for P300 and R300, respectively). The reason for the worse fitness by Freundlich model was that the supply of adsorption site was not infinite on studied biochars surface. Because of the variety of parameters and conditions, direct comparison was impossible. However, the adsorption capacity of lead onto the biochars exceeded or was comparable to other adsorbents reported in literature qualitatively [23-28].
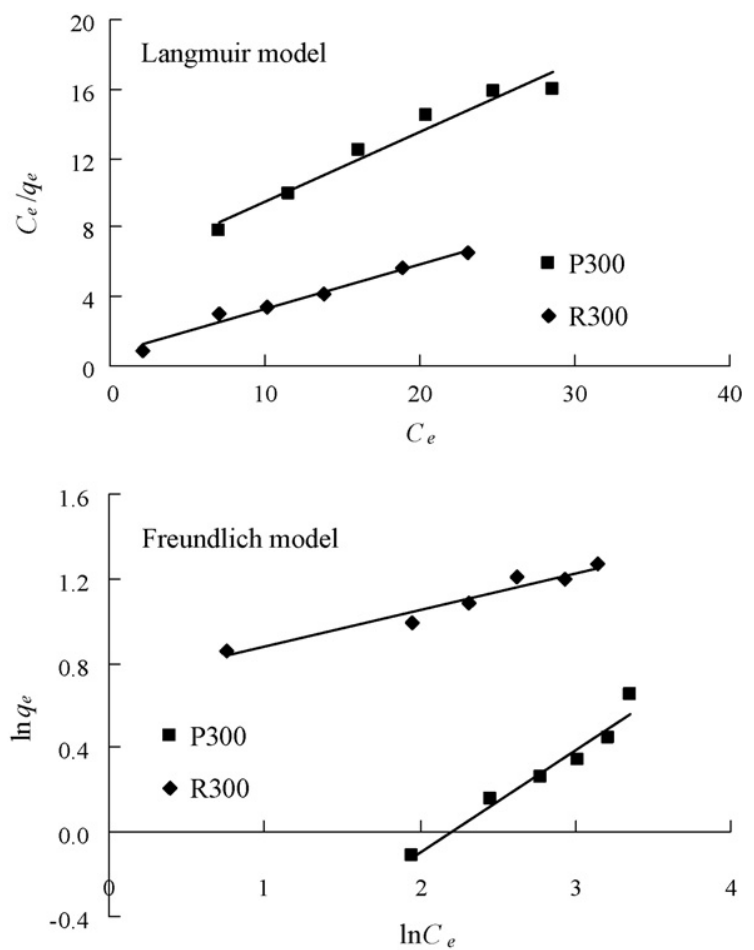

Fig. 6. Langmuir and Freundlich isotherm models for lead adsorption onto P300 and $\mathrm{R} 300$ at $298 \mathrm{~K}$

\subsubsection{Adsorption kinetics}

Pseudo-first-order (Eq. (3)) and pseudo-second-order (Eq. (4)) were employed to study the lead adsorption mechanism onto P300 and R300.

$\log \left(q_{e}-q_{t}\right)=\log q_{e}-\frac{k_{1} t}{2.303}$

$\frac{t}{q_{t}}=\frac{1}{k_{2} q_{e}^{2}}+\frac{t}{q_{e}}$

where $q_{t}$ and $q_{e}(\mathrm{mg} / \mathrm{g})$ are adsorbed lead amount at time $t(\mathrm{~h})$ and equilibrium, $k_{1}(1 / \mathrm{h})$ and $k_{2}(\mathrm{~g} /(\mathrm{mgh}))$ are the rate constant for the pseudo-first-order and pseudo-second-order adsorption kinetics, respectively.

The linear plots of value $\log \left[\left(q_{e}-q_{t}\right) / q_{e}\right]$ against time $t$ can give the pseudo-first-order adsorption rate constant $k_{1}$ from the slopes and $q_{e}$ can be calculated from the intercept. The corresponding values of $k_{1}, q_{e}$ and $R^{2}$ are presented in Table 3 at tested temperatures. As can be seen from the results, the correlation coefficients were low $\left(R^{2}<0.90\right)$. Also $q_{e}$ values calculated from the plots were lower than the experimental data. Therefore, it may conclude that lead adsorption system did not follow pseudo-first-order equation perfectly and higher orders rate equations should be applied to test the applicability.

By plotting $t / q_{t}$ against time $t$, the pseudo-second-order adsorption rate constant $k_{2}$ and $q_{e}$ were determined from the slope and intercept of the plot. The values $k_{2}$, calculated $q_{e}$ values and the correction coefficients $R^{2}$ are given in Table 3 and Fig. 7 shows the plots with initial lead concentration $20 \mathrm{mg} / \mathrm{L}$ at tested temperatures. As can be seen from the results that the correlation coefficients $R^{2}$ were high ( $>0.99$ ). The well fitting by the data suggested that pseudosecond-order model can be considered in the present adsorption system.
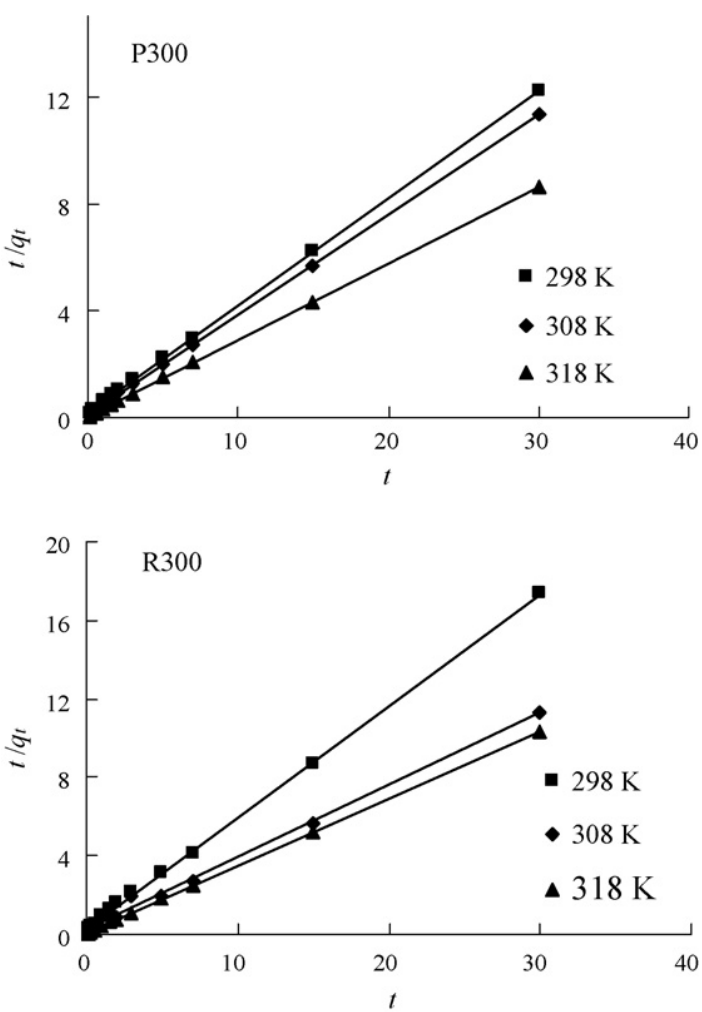

Fig. 7. Pseudo-second-order kinetics for lead adsorption onto P300 and R300 (initia lead concentration $20 \mathrm{mg} / \mathrm{L}$ ). 
Table 3

Parameters of pseudo-first-order and pseudo-second-order kinetics models for lead adsorption onto P300 and R300.

\begin{tabular}{|c|c|c|c|c|c|c|c|c|}
\hline \multirow[t]{2}{*}{ Sample } & \multirow[t]{2}{*}{$T(\mathrm{~K})$} & \multirow{2}{*}{$\frac{C_{\text {ini }}}{(\mathrm{mg} / \mathrm{L})}$} & \multicolumn{3}{|c|}{ Pseudo-first-order model } & \multicolumn{3}{|c|}{ Pseudo-second-order model } \\
\hline & & & $q_{e}$ & $k_{1}$ & $R^{2}$ & $q_{e}$ & $k_{2}$ & $R^{2}$ \\
\hline \multirow{9}{*}{ P300 } & \multirow[t]{3}{*}{298} & 10 & 0.89 & 0.45 & 0.84 & 1.53 & 1.40 & 0.99 \\
\hline & & 15 & 0.87 & 0.12 & 0.89 & 2.13 & 0.52 & 0.99 \\
\hline & & 20 & 0.87 & 0.08 & 0.81 & 2.50 & 0.86 & 0.99 \\
\hline & \multirow[t]{3}{*}{308} & 10 & 0.90 & 0.95 & 0.73 & 1.76 & 1.96 & 0.99 \\
\hline & & 15 & 0.86 & 0.54 & 0.75 & 2.52 & 1.13 & 0.99 \\
\hline & & 20 & 0.87 & 0.22 & 0.75 & 2.68 & 1.07 & 0.99 \\
\hline & \multirow[t]{3}{*}{318} & 10 & 0.91 & 0.69 & 0.69 & 1.85 & 1.96 & 0.99 \\
\hline & & 15 & 0.99 & 0.13 & 0.73 & 2.86 & 1.03 & 0.99 \\
\hline & & 20 & 0.88 & 0.46 & 0.76 & 3.50 & 1.66 & 0.99 \\
\hline \multirow{9}{*}{ R300 } & \multirow[t]{3}{*}{298} & 10 & 0.53 & 0.08 & 0.79 & 0.96 & 1.12 & 0.99 \\
\hline & & 15 & 0.59 & 0.11 & 0.75 & 1.06 & 0.65 & 0.99 \\
\hline & & 20 & 0.89 & 0.12 & 0.77 & 1.76 & 1.30 & 0.99 \\
\hline & \multirow[t]{3}{*}{308} & 10 & 0.32 & 0.10 & 0.85 & 1.25 & 2.73 & 0.99 \\
\hline & & 15 & 0.50 & 0.11 & 0.83 & 1.67 & 1.48 & 0.99 \\
\hline & & 20 & 0.86 & 0.15 & 0.67 & 2.73 & 0.47 & 0.99 \\
\hline & \multirow[t]{3}{*}{318} & 10 & 0.37 & 0.12 & 0.81 & 1.51 & 2.26 & 0.99 \\
\hline & & 15 & 0.72 & 0.13 & 0.83 & 1.96 & 0.93 & 0.99 \\
\hline & & 20 & 0.61 & 0.12 & 0.82 & 2.91 & 1.55 & 0.99 \\
\hline
\end{tabular}

Mathematical model described by Weber and Morris [29] was use to provide the definite adsorption mechanism.

$q_{t}=K_{d} \sqrt{t}+C$

where $K_{d}\left(\mathrm{mg} /\left(\mathrm{g} \mathrm{h}^{1 / 2}\right)\right)$ is the intra-particle diffusion rate constant, $C$ ( $\mathrm{mg} / \mathrm{g}$ ) adsorption constant, and $q_{t}(\mathrm{mg} / \mathrm{g})$ is adsorbed lead amount at time $t(\mathrm{~h})$.

The plot of $q_{t}$ against $t^{1 / 2}$ would result in a straight line if the ratelimiting is the intra-particle diffusion. Moreover, the line would pass through the origin if the intra-particle diffusion is the only ratecontrolling step. The result of linearity test of $q_{t}$ against $t^{1 / 2}$ is shown in Fig. 8, and Table 4 shows $K_{d}$ and $C$ obtained from the plot slopes
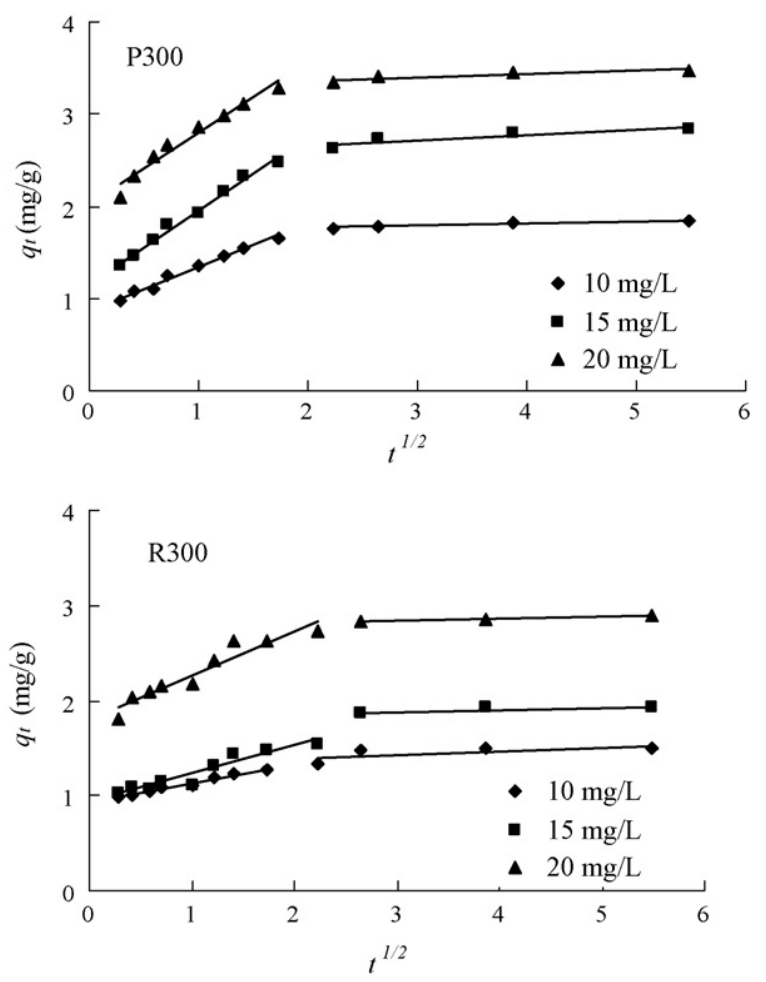

Fig. 8. Intra-particle diffusion kinetics for lead adsorption onto P300 and R300 (adsorbent dose $5 \mathrm{~g} / \mathrm{L}$; temperature $318 \mathrm{~K}$ ). and intercepts at $298 \mathrm{~K}$. As can be seen from the results, both plots of P300 and R300 gave similar patterns at different adsorbent dose. In the present study, the plots of $q_{t}$ against $t^{1 / 2}$ obtained from lead removal onto P300 and R300 did not pass through the origin and were not linear over the whole time range. The linearity was evaluated separately. For the first proportion, diffusion model was that mass of lead ions transferred across the bulk solution to the solution around biochar surface and the second linearity showed lead ions diffusion into adsorbent surface pores. The higher slopes for the first proportion implied that lead ions transferred from bulk solution to biochar surface was faster. The lower slopes of the second proportion suggested intra-particle diffusion was rate-controlling step after a long contact time.

\subsubsection{Thermodynamic studies}

The thermodynamic parameters such as Gibbs free energy $\left(\Delta G^{\circ}\right)$, enthalpy $\left(\Delta H^{\circ}\right)$ and entropy $\left(\Delta S^{\circ}\right)$ for the process were estimated by the following equations:

$K_{e}=\frac{q_{e}}{C_{e}}$

$\Delta G^{\circ}=-R T \ln K_{e}$

$\Delta G^{\circ}=\Delta H^{\circ}-T \Delta S^{\circ}$

$\ln K_{e}=\frac{\Delta S^{\circ}}{R}-\frac{\Delta H^{\circ}}{R T}$

where $q_{e}(\mathrm{mg} / \mathrm{g})$ is the amount of lead adsorbed onto the biochars from the solution at equilibrium, $C_{e}(\mathrm{mg} / \mathrm{L})$ the equilibrium concentration of lead in the solution, $R(\mathrm{~J} / \mathrm{mol} \mathrm{K})$ the gas constant $8.314, T$ (K) the absolute temperature, and $K_{e}(\mathrm{~L} / \mathrm{g})$ is the adsorption equilibrium constant.

Table 4

Intra-particle diffusion parameters and correlation coefficients for lead adsorption onto P300 and R300 at $298 \mathrm{~K}$.

\begin{tabular}{llllll}
\hline Sample & $C_{\text {ini }}(\mathrm{mg} / \mathrm{L})$ & & \multicolumn{3}{l}{ Intra-particle diffusion } \\
\cline { 5 - 6 } & & & $K_{d}$ & $C$ & $R^{2}$ \\
\hline P300 & 10 & 0.48 & 0.86 & 0.98 \\
& 15 & 0.80 & 1.61 & 0.99 \\
& 20 & 0.78 & 2.01 & 0.96 \\
R300 & 10 & & & 0.93 & 0.98 \\
& 15 & 0.20 & 0.93 & 0.91 \\
& 20 & 0.30 & 1.80 & 0.91 \\
\hline
\end{tabular}




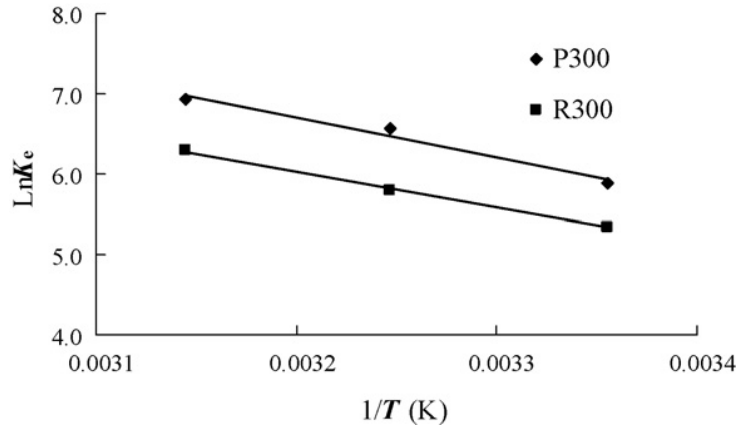

Fig. 9. Plots of $\ln K_{e}$ against $1 / T$ for lead adsorption onto P300 and R300.

Table 5

Thermodynamic parameters of lead adsorption onto P300 and R300.

\begin{tabular}{|c|c|c|c|c|}
\hline \multirow[t]{2}{*}{ Sample } & \multirow[t]{2}{*}{ Temperature $T(\mathrm{~K})$} & \multicolumn{3}{|c|}{ Thermodynamic parameters } \\
\hline & & $\Delta G^{\circ}(\mathrm{kJ} / \mathrm{mol})$ & $\Delta H^{\circ}(\mathrm{kJ} / \mathrm{mol})$ & $\Delta S^{\circ}(\mathrm{J} / \mathrm{mol} \mathrm{K})$ \\
\hline P300 & $\begin{array}{l}298 \\
308 \\
318\end{array}$ & $\begin{array}{l}-14.68 \\
-16.55 \\
-18.42\end{array}$ & 41.10 & 187.15 \\
\hline R300 & $\begin{array}{l}298 \\
308 \\
318\end{array}$ & $\begin{array}{l}-13.20 \\
-14.89 \\
-16.58\end{array}$ & 37.13 & 168.88 \\
\hline
\end{tabular}

The values $q_{e}$ of the pseudo-second-order model in Table 3 were used to obtain the values of $C_{e}$ and $K_{e}$. By plotting $\ln K_{e}$ against $1 / T$, the values of $\Delta H^{\circ}$ and $\Delta S^{\circ}$ can be estimated from the slopes and intercepts and the values of $\Delta G^{\circ}$ can be obtained from the corresponding values of $\Delta H^{\circ}$ and $\Delta S^{\circ}$. The value of $\Delta G^{\circ}$ suggests the spontaneous nature of the adsorption process and give the information about the type of adsorption: chemical or physical adsorption. Generally, the change of free energy for physical adsorption is in the range of -20 to $0 \mathrm{~kJ} / \mathrm{mol}$, while chemical adsorption is between -400 and $-80 \mathrm{~kJ} / \mathrm{mol}[30]$. The experimental results are shown in Fig. 9 and Table 5 . The $\Delta G^{\circ}$ for tested temperatures was between -13 and $-19 \mathrm{~kJ} / \mathrm{mol}$ during adsorption and this value was in the range of physical adsorption, showing that lead adsorption was a physical process. The positive value of $\Delta H^{\circ}$ suggested that the adsorption was endothermic process and this result was confirmed by the effect of temperature on lead removal. Gibbs free energy $\Delta G^{\circ}$ during the adsorption process was negative for all tested temperatures, which was corresponding to the spontaneous speciality of lead adsorption onto P300 and R300.

\section{Conclusions}

This study demonstrated the feasibility of biochars from hydrothermal conversion of biomass as adsorbents for lead removal from aqueous solution. Based on the obtained results, the following conclusions can be drawn:

- Irregular surface and much more oxygen-containing groups were developed after hydrothermal treatment, which was significantly important for biochars as adsorbent.

- Lead adsorption onto the biochars was strongly influenced by the solution $\mathrm{pH}$. The adsorption was a physical endothermic process.

- The adsorption kinetics was best described by pseudo-secondorder kinetic model and the adsorption data could be well fitted by Langmuir model. The maximum lead adsorption capacities were 4.25 and $2.40 \mathrm{mg} / \mathrm{g}$ onto P300 and R300 at $318 \mathrm{~K}$, respectively.

\section{Acknowledgments}

This research was supported by the National Key Technology R \& D Program (2008BAC32B03) and the National Basic Research Program (2007CB407303) of China.

\section{References}

[1] S.E. Bailey, T.J. Olin, R.M. Bricka, D.D. Adrian, A review of potentially low-cost sorbents for heavy metals, Water Res. 33 (1999) 2469-2479.

[2] J.M. Dias, M.C.M. Alvim-Ferraz, M.F. Almeida, J. Rivera-Utrilla, M. Sanchez-Polo, Waste materials for activated carbon preparation and its use in aqueous-phase treatment: a review, J. Environ. Manage. 85 (2007) 833-846.

[3] J.F.P. Gordon McKay, Equilibrium parameters for the sorption of copper, cadmium and zinc ions onto peat, J. Chem. Technol. Biotechnol. 69 (1997) 309320.

[4] M. Sciban, B. Radetic, Z. Kevresan, M. Klasnja, Adsorption of heavy metals from electroplating wastewater by wood sawdust, Bioresour. Technol. 98 (2007) 402-409.

[5] W.T. Tan, S.T. Ooi, C.K. Lee, Removal of $\mathrm{Cr}(\mathrm{VI})$ from solution by coconut husk, palm pressed fibers, Environ. Technol. 14 (1993) 277-282

[6] J.P. Chen, L. Yang, Chemical modification of sargassum sp. for prevention of organic leaching and enhancement of uptake during metal biosorption, Ind Eng. Chem. Res. 44 (2005) 9931-9942.

[7] W.S. Wan Ngah, M.A.K.M. Hanafiah, Removal of heavy metal ions from wastewater by chemically modified plant wastes as adsorbents: a review, Bioresour. Technol. 99 (2008) 3935-3948.

[8] T. Budinova, E. Ekinci, F. Yardim, A. Grimm, E. Bjornbom, V. Minkova, M. Goranova, Characterization and application of activated carbon produced by $\mathrm{H}_{3} \mathrm{PO}_{4}$ and water vapor activation, Fuel Process. Technol. 87 (2006) 899-905.

[9] D. Kalderis, D. Koutoulakis, P. Paraskeva, E. Diamadopoulos, E. Otal, J.O. Valle d. C. Fernandez-Pereira, Adsorption of polluting substances on activated carbons prepared from rice husk and sugarcane bagasse, Chem. Eng. J. 144 (2008) 4250.

[10] O.S. Amuda, A.A. Giwa, I.A. Bello, Removal of heavy metal from industria wastewater using modified activated coconut shell carbon, Biochem. Eng. J. 36 (2007) 174-181.

[11] S. Karagoz, T. Bhaskar, A. Muto, Y. Sakata, T. Oshiki, T. Kishimoto, Lowtemperature catalytic hydrothermal treatment of wood biomass: analysis of liquid products, Chem. Eng. J. 108 (2005) 127-137.

[12] S. Karagoz, T. Bhaskar, A. Muto, Y. Sakata, Hydrothermal upgrading of biomass: effect of $\mathrm{K}_{2} \mathrm{CO}_{3}$ concentration and biomass/water ratio on products distribution, Bioresour. Technol. 97 (2006) 90-98.

[13] W. Feng, H.J. Van der kooi, J. de Swaan Arons, Phase equilibria for biomass conversion processes in subcritical and supercritical water, Chem. Eng. J. 98 (2004) 105-113.

[14] S. Karagoz, T. Bhaskar, A. Muto, Y. Sakata, Comparative studies of oil compositions produced from sawdust, rice husk, lignin and cellulose by hydrothermal treatment, Fuel 84 (2005) 875-884.

[15] C. Zhong, X. Wei, A comparative experimental study on the liquefaction of wood Energy 29 (2004) 1731-1741.

[16] H.P. Boehm, Chemical identification of surface groups, in: D.D. Eley, H. Pines, P.B. Weisz (Eds.), Advances in Catalysis, vol. 16, Academic Press, New York, 1966, p. 179.

[17] T.J. Bandosz, J. Jagiello, C. Contescu, J.A. Schwarz, Characterization of the surfaces of activated carbons in terms of their acidity constant distributions, Carbon 31 (1993) 1193-1202.

[18] M. Guerrero, M.P. Ruiz, M.U. Alzueta, R. Bilbao, A. Millera, Pyrolysis of eucalyptus at different heating rates: studies of char characterization and oxidative reactivity, J. Anal. Appl. Pyrol. 74 (2005) 307-314.

[19] Z. Liu, F.-S. Zhang, Effects of various solvents on the liquefaction of biomass to produce fuels and chemical feedstocks, Energy Convers. Manage. 49 (2008) 3498-3504.

[20] I. Kula, M. Ugurlu, H. Karaoglu, A. Celik, Adsorption of Cd(II) ions from aqueous solutions using activated carbon prepared from olive stone by $\mathrm{ZnCl}_{2}$ activation, Bioresour. Technol. 99 (2008) 492-501.

[21] G. Blaquez, F. Hernainz, M. Calero, L.F. Ruiz-Nunez, Removal of cadmium ions with olive stones: the effect of some parameters, Process Biochem. 40 (2005) 2649-2654.

[22] Z. Aksu, T. Kutsal, A bioseparation process for removing $\mathrm{Pb}$ (II) ions from wastewater by using C. vulgaris, J. Chem. Technol. Biotechnol. 52 (1991) 108-118.

[23] Y. Bulut, Z. Tez, Removal of heavy metal ions by modified sawdust of walnut, Fresen. Environ. Bull. 12 (2003) 1499-1504.

[24] S.J. Allen, G. McKay, J.F. Porter, Adsorption isotherm models for basic dye adsorption by peat in single and binary component systems, J. Colloid Interf. Sci. 280 (2004) 322-333.

[25] S.E. Abdel-Aal, Y.H.G.A.M. The use of wood pulp and radiation-modified starch in wastewater treatment, J. Appl. Polym. Sci. 99 (2006) 2460-2469.

[26] S.K. Ouki, M. Kavannagh, Performance of natural zeolites for the treatment of mixed metal-contaminated effluents, Waste Manage. Res. 15 (1997) 383394.

[27] F.O.O. Faraday, Removal of lead from water by adsorption on a kaolinitic clay, J Chem. Technol. Biotechnol. 65 (1996) 363-369. 
[28] D. Mohan, J.C.U. Pittman, M. Bricka, F. Smith, B. Yancey, J. Mohammad, P.H. Steele, M.F. Alexandre-Franco, V. Gez-Serrano, H. Gong, Sorption of arsenic, cadmium, and lead by chars produced from fast pyrolysis of wood and bark during bio-oil production, J. Colloid Interf. Sci. 310 (2007) 57-73.
[29] W.J. Weber, J.C. Morris, Kinetics of adsorption on carbon from solution, J. Sanit. Eng. Div. Am. Soc. Civil Eng. 89 (1963) 31-59.

[30] P.W. Atkins, Physical Chemistry, fourth ed., Oxford University Press, London, 1990, pp. 884-890. 